\title{
Informatization Workshop Personnel Management System Based on MES
}

\author{
Zhen ZHANG ${ }^{1, a}$, Feng-Xiang YOU ${ }^{1, b}$ \\ ${ }^{1}$ Electrical and Mechanical Department of Suzhou University, Suzhou Jiangsu, 215131 \\ a490665044@qq.com, byoufengxiang98@163.com
}

Keywords: MES, Informatization workshop, Personnel management.

\begin{abstract}
In the context of "Made in China 2025", most of manufacturing began to build the informatization and digitization production workshop. Although most of the manufacturing introduced the automation equipment and MES (Manufacturing Execution System), they focus only on information about machines or products during production, but ignore the management of personnel information. This paper proposed a general information production workshop staff management system model for an auto parts production workshop to solve the personnel information can't be collected and traced, staff skills management is not perfect, productivity statistics inaccurate problems, so as to realize the effective monitoring and paperless management of the personnel information, and through the statistical theory to determine the level of staff skills, so as to improve the efficiency of workshop staff management and product quality control play a key role.
\end{abstract}

\section{Introduction}

In the era of "Internet +", "Industry 4.0" and "Made in China 2025" have become familiar with most manufacturing industries. Facing the highly competitive and rapidly changing market environment and product diversification, personalized customer needs and speed up manufacturing to achieve the pace of the informatization and digitization. In traditional production workshop, due to the lack of real-time accurate information on the production site, leading to information failure, the workshop production process as a "black box operation", Workshop site problems can't be real-time warning and feedback, it is hard for manager to find and solve the problem in time; and due to the lack of production data acquisition or machine data collection, the traceability of production process can't be realized, which can seriously affect the production efficiency and product quality of the workshop.

With the development of "intelligent manufacturing", MES (Manufacturing Execution System) has become the core of intelligent manufacturing. Every module in MES has been continuously improved by scholars, and the practical application of MES has already become mature. MES is defined as a shop floor management information system between the upper level plan management system and the underlying industrial control. In the mid-1990s the concept of the MES developed by AMR (American Advanced Manufacturing Research Center), after then, MESA (Manufacturing Execution Solutions Association) describes the following 12 function groups:

Detailed planning; Resource management; Registration and display of the current status of resources; Document management; Material management; Performance analysis; Order management; Maintenance management; Process management; Quality management; Data collection and acquisition; Product tracking and genealogy[1,2,3].

Starting from the establishment of workshop production management system for agile manufacturing enterprises, ZHANG[4] analyzed and discussed the functions and application characteristics of MES, and put forward the idea of using advanced manufacturing execution system thought and software to build agile workshop system. In view of the complexity of the application and development of the manufacturing execution system, CHAI[5] proposed a flexible application 
framework for the manufacturing execution system. WU[6,7]et al. have studied the function structure, data acquisition module and production monitoring module of discrete MES system in detail, and established corresponding functional models, information models and process models by using the structured modeling method. QIN[8] used RFID data acquisition mode and ZigBee data transmission technology to achieve real-time data acquisition of data processing time, processing end time, product processing equipment, processing personnel and other data in discrete manufacturing workshop production process. WANG[9] research the design and implementation of MES system for automobile factory. LI[10] aims at the auto parts production enterprises, the discrete workshop production management model of MES design using RFID technology and Apache Thrift framework, and proposes the use of Android client based on the production of remote monitoring and management. Milagros Rolón[11] et al. studied the problem of multi agent, which will continue to optimize the process route by reliability and cost.

For most small and medium-sized discrete manufacturing industry, the people in the production workshop dominate. Most of the production processes in the workshop must be completed by people. If the workshop worker can't be effectively controlled, the production efficiency and product quality must be affected. However, the research on MES mentioned above, though it has been involved in various manufacturing industries, lacks the content of personnel management in the workshop. Starting from the actual lack of personnel management in the production workshop, this model was established under the MES standard framework.

\section{Related Requirements}

Through a detailed investigation and analysis of a car seat belt production workshop, the main problems in personnel management of the current production workshop are summarized as follows:

\section{No Worker Information Collection}

Data acquisition in the process of production includes personnel information related data, equipment related data, material related data, process status and processing time related data and workshop environment related data. Only the above data can be collected in order to be comprehensive and real-time tracking. At present, the workshop can't collect worker information and can't monitor worker status in real time.

\section{No POKA-YOKE}

There are many kinds of products in the production workshop, it is impossible to determine whether an employee can produce a type of product. Considering product quality control of the production process, POKA-YOKE is necessary to workers, each worker can only do what he can do. Due to the current workshop staff can freely process all products, resulting in product quality can’t be guaranteed.

\section{No Process Traceability}

In workshop, each employee must manually record their own employee id and products on the recording card. After work, the team leader count the data and import it into the computer. Due to the recording card is flowing with the product in the workshop, the information can't be kept intact.

\section{No Quantization to Staff Skill Level}

For new employees, after training, they need real-time monitoring when processing products. The 
new staff on-line to be led by the old staff to operate, and whether the new staff compliance standards mainly by the workshop manager for the subjective judgments, no data related to the production process.

\section{Inaccurate Statistics in Personnel Productivity}

Only the employees who are processing the products count their actual productivity and the number of unqualified ones, record them in a paper form, and then summarize them by the team leader. Then they calculate the production hours, production efficiency, overtime hours and abnormal working hours uniformly. There are data recording is not accurate, tedious statistical process and other issues.

In view of the above problems existing in the workshop, a MES-based information workshop personnel management system is designed to effectively manage the staff.

\section{Basic Framework}

\section{System Framework}

This personnel management system needs to call the database of MES. The product information of the production process recorded in the MES needs to be bound with the personnel information, and then the information is stored in the database. The system framework is as shown in Fig. 1.

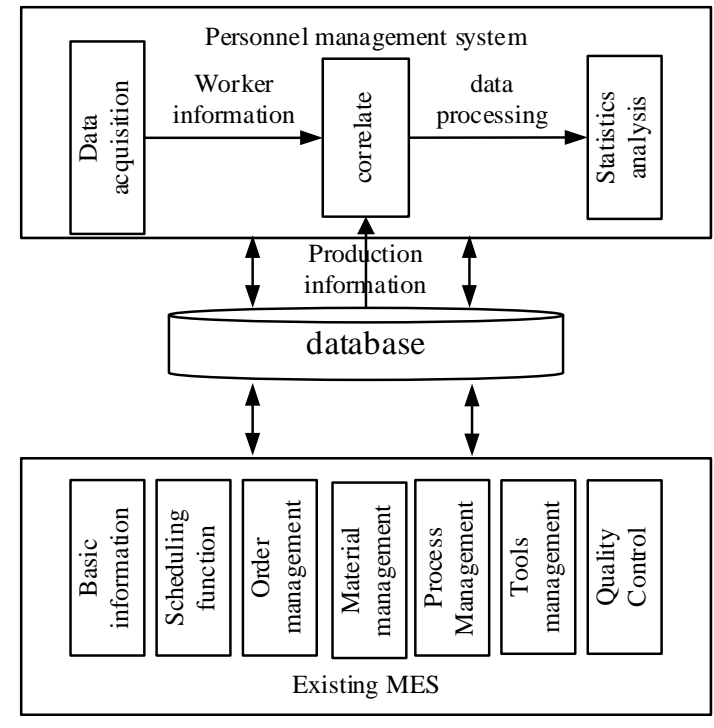

Fig.1. System Framework

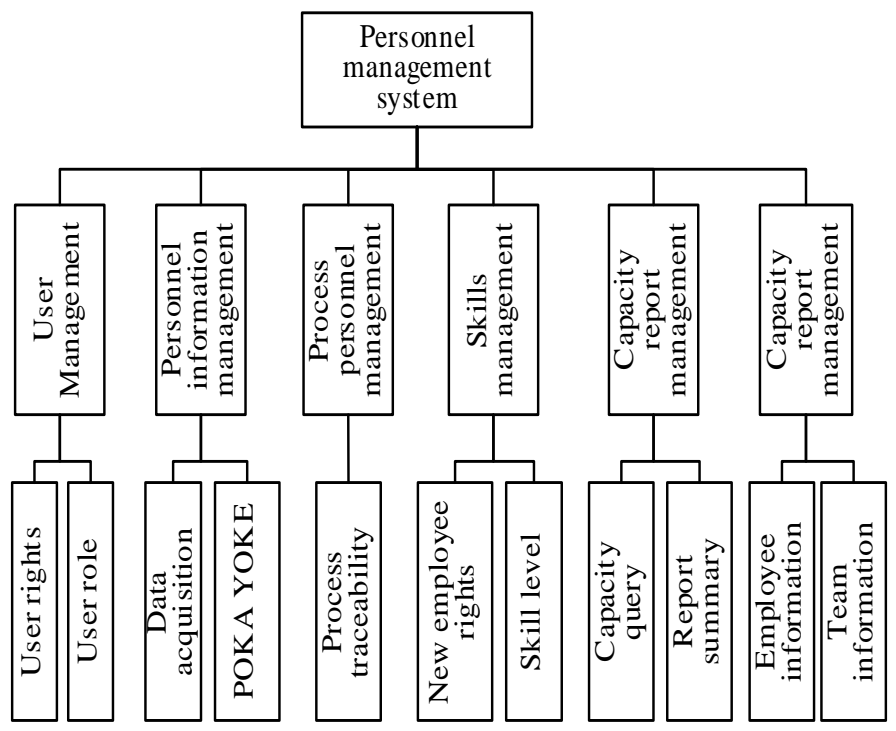

Fig. 2. System Function Model

\section{System Function Model}

According to the workshop's current problems, the function of personnel management system is designed, including user management, personnel information management, personnel production process management, staff skill level management, capacity report management, personnel basic data, the functional model shown in Fig. 2.

\section{Function Analysis}

\section{Personnel Information Management}

1) Using RFID multi-function machine to collect worker information, and it will be recorded in the 
database by brushing cards. In the workshop, each workstation is equipped with an RFID multi-function machine, each worker has a RFID card. When employees are on or off work, they must brush cards, and the system will record the time and worker information. It also includes the process of departure, abnormal pause, rest and other related information records.

2) The POKA-YOKE is in the process of brushing card. The system will match the worker information with the product in the order, if the worker can't produce this product, and it will have a warning. The decision process shown in Fig. 3.

The staff skill matrix is the basic data that is maintained in advance, and is shared with the following staff skill management. The simplified form is shown in Table 1.

Table 1. Staff skill matrix

\begin{tabular}{|l|l|l|l|l|l|}
\hline WorkerID & ProductionID & SkillLevel & CreationDate & Reviewer & Updated Date \\
\hline 001 & P001 & 2 & $2017-09-01$ & A & $2017-09-01$ \\
\hline 001 & P002 & 2 & $2017-09-01$ & A & $2017-09-02$ \\
\hline$\ldots$ & $\ldots$ & $\ldots$ & $\ldots$ & $\ldots$ & $\ldots$ \\
\hline 002 & P003 & 1 & $2017-09-01$ & B & $2017-09-01$ \\
\hline
\end{tabular}

\section{Personnel Production Process Management}

It is mainly in the process of product processing, each workstation worker need to barcode each product, and then the system will automatically bind the product and worker information, stored in the database. Regardless of the product is good or bad, it will be entered into the relevant staff production process record sheet, in order to achieve the traceability of production.

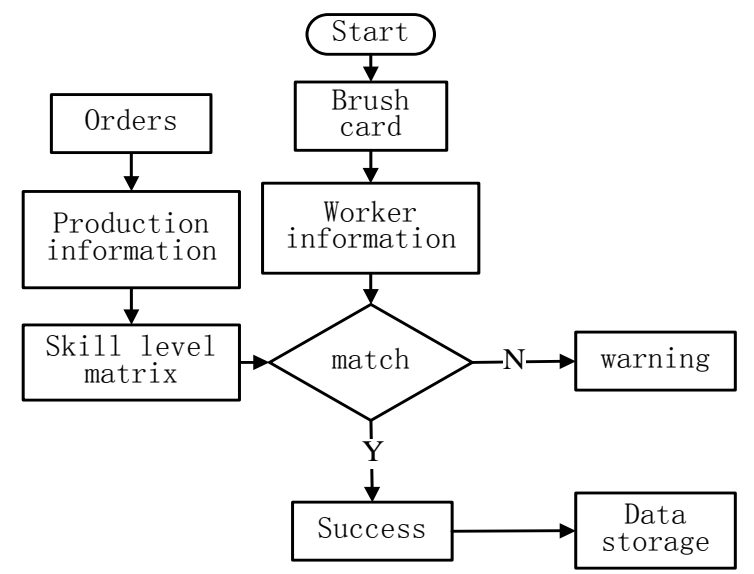

Fig.3. Decision process

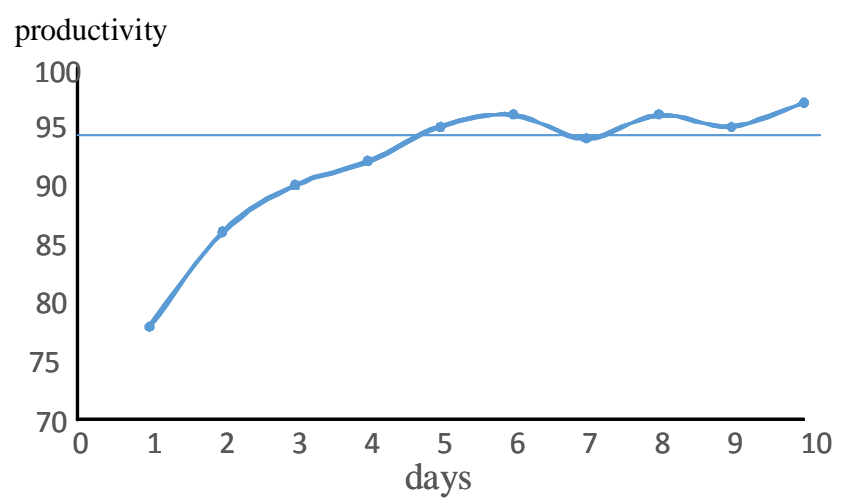

Fig. 4. "Climbing" curve

\section{Staff Skill Level Management}

It is the performance of each employee processing a product proficiency, this feature includes the new employee operation rights management and skills level upgrade management.

1) New employee operation rights management. For a new worker, he has a skill level of 1 for a product, whereas a worker with a skill level of 1 is not able to process the product individually and only under the guidance of an older worker. When aworker brushes cards, the system determines the skill level of the worker according to the skill level matrix. If it is 1 , the system prompts that the worker can't be processed independently, and the old worker needs to brush the card at the same time to process the new product. 
2) Staff skills level upgrade management. Aworker's proficiency in a product is determined by the qualified capacity of the product being processed. When the new worker's qualified capacity reaches and remains within a standard range, the new worker is judged to have the ability to process the product and the system automatically increases his skill level to level 2, indicating that the worker has the ability to process the product independently.

The qualified capacity of the each worker will increase as their operational proficiency increases. Real-time statistics on their production capacity will be made into a graph which is a "climbing" curve with gradual increase in production capacity. The curve is shown in the Fig. 4.

The system will automatically count and analyze whether a new employee's production capacity is stable within a certain period of time (5-10 days). If it is stable within a certain standard capacity range, it will be determined that the employee has mastered the skills of processing this product. The skill level in staff skill matrix will be updated automatically. However, since the standard capacity range belongs to an empirical value, a confidence interval is set as the standard capacity range based on statistics.

For the skilled workers, their productivity obeys $\mathrm{N}\left(\mu, \sigma^{2}\right)$ distribution, and the confidence interval of the mean $\mu$ can be obtained.

Suppose that the given confidence level is $1-\alpha$, and $X_{1}, X_{2}, \cdots, X_{n}$ are the sample of the overall $\mathrm{N}\left(\mu, \sigma^{2}\right)$. The sample mean and variance are $\bar{X}$ and $S^{2}$. Since the overall $\sigma^{2}$ is unknown, we consider that $S^{2}$ is the unbiased estimateof $\sigma^{2}$. According to the related theorem of sampling distribution, they can be expressed in Eq. 1, Eq. 2 and Eq. 3.

$$
\frac{\bar{X}-\mu}{S / \sqrt{n}} \sim t(n-1)
$$

And

$$
\mathrm{P}\left\{\bar{X}-\frac{S}{\sqrt{n}} t_{\frac{\alpha}{2}}(n-1)<\mu<\bar{X}+\frac{S}{\sqrt{n}} t_{\frac{\alpha}{2}}(n-1)\right\}=1-\alpha
$$

Thus, we can get the confidence interval of $\mu$, and its confidence level is $1-\alpha$.

$$
\left(\bar{X} \pm \frac{S}{\sqrt{n}} t_{\frac{\alpha}{2}}(n-1)\right)
$$

A set of productivity data is randomly selected from all the historical proficiency data of skilled workers and then a confidence interval of $1-\alpha$ (usually 0.95 ) is calculated from the above relevant confidence interval theory. Then, the confidence interval is used as a standard production capacity range to judge whether the new employee productivity is stable, so as to raise the staff skill level.

\section{Capacity Report Management}

All employee productivity data will be collected and summarized. Managers can inquire personnel productivity, including the actual production hours, actual production capacity, planned completion rate, abnormal working hours and overtime working hours per employee. All processes are automatically collected by the system to avoid incomplete data and to achieve paperless management. 


\section{Conclusion}

In this paper, a manual production-oriented auto parts production workshop exist personnel control problems, the design of the personnel production management system to achieve the production workshop paperless personnel management, staff POKA-YOKE and traceability, and through the statistical theory, a quantitative assessment of staff skills is proposed. The system not only enhances management's management efficiency of production workshop personnel, but also strengthens the quality control in the production process and effectively improves product yield.

\section{References}

[1] Information on http://www.amrc.com.

[2]MESA International, “MES Functionalities \& MRP to MES Data Flow Possibilities” White Paper 3 (Pittsburgh: Manufacturing Execution Systems Assoc. 1997).

[3] Jürgen Kletti. Manufacturing Execution Systems - MES. Springer, 2007.

[4] Shu-Ting ZHANG,Lian-Jun YANG. Manufacturing Executing System for Agile Shop Floor, New Technology \& New Process. 12(2000), 2-4. (In Chinese)

[5] Yong-Sheng CHAI, Shu-Dong SUN,Xiu-Li WU,Peng LI. Flexible application framework for manufacturing execution systems. Computer Applications. 3(2005), 679-681. (In Chinese)

[6] Mei-Lei WU. Research of discrete Manufacturing Execution System (MES). Shandong University, 2007.(In Chinese)

[7] Ji-Wei LV. Information Acquisition and MethodsReseach of MES in Production Process inDiscrete Manufacturing Workshop. Chongqing University, 2011. (In Chinese)

[8] Rui QIN. Systematic Research of Discrete Manufacturing Workshop Data Acquisition of Production Process Based on Manufacturing Execution System. Kunming University of Science and Technology. 2016.(In Chinese)

[9] Xiao-Wei WANG. Design and Implementation of Car Plant MES System. East China University of Science and Technology. 2016.(In Chinese)

[10] Chao LI, Li-wei GAO. Production Management System Designing of Discrete Workshop Based on MES. Modular Machine Tool \& Automatic Manufacturing Technique, 5(2017), 149-151.(In Chinese)

[11]Milagros Rolón; Ernesto Martínez; Agent learning in autonomic manufacturing execution systems for enterprise networking. Computers \& Industrial Engineering, 63(2012), 901-925. 